\title{
Patient-reported outcomes of dual bronchodilator fixed-dose combination versus bronchodilator monotherapy in individuals with COPD
}

This article was published in the following Dove Press journal: International Journal of Chronic Obstructive Pulmonary Disease

\author{
Charlie Strange' \\ Valery Walker ${ }^{2}$ \\ Michael DePietro ${ }^{3}$ \\ Junliang Tong ${ }^{2}$ \\ Jonathan Kurlander ${ }^{2}$ \\ Maureen Carlyle ${ }^{2}$ \\ Lauren A Millette ${ }^{3}$ \\ Eric Wittbrodt ${ }^{4}$ \\ 'Division of Pulmonary and Critical Care \\ Medicine, Medical University of South \\ Carolina, Charleston, SC, USA; ${ }^{2}$ Health \\ Economics and Outcomes Research, \\ Optum, Inc., Eden Prairie, MN, USA; ${ }^{3}$ US \\ Medical Affairs, AstraZeneca, \\ Wilmington, DE, USA; ${ }^{4}$ Health \\ Economics and Outcomes Research, \\ AstraZeneca, Wilmington, DE, USA
}

Correspondence: Valery Walker Optum, Inc., I 1000 Optum Circle, Eden Prairie, MN 55344, USA

Email Valery.walker@optum.com
Background: This study compared real-world patient-reported outcomes (PROs) measured by the Clinical COPD Questionnaire (CCQ), the London Chest Activities of Daily Living (LCADL) scale, and the Work Productivity and Activity Impairment (WPAI) questionnaire between individuals with COPD initiating LAMA/LABA fixed-dose combination (FDC) dual therapy versus either long-acting muscarinic antagonist (LAMA) or long-acting beta2agonist (LABA) monotherapy.

Methods: Individuals with COPD aged $\geq 40$ years initiating a LAMA/LABA FDC dual therapy or a LAMA or LABA monotherapy (index date $=$ first prescription date) between January 1, 2016 and December 31, 2016 were identified from a large US administrative claims database. Individuals were excluded if they were prescribed an inhaled corticosteroid (ICS) or ICS/LABA two months prior to the index date or were diagnosed with cystic fibrosis, idiopathic pulmonary fibrosis, or asthma. The cohorts were propensity score matched (PSM) 1:1 for COPD severity using baseline measures. Each participant completed a survey.

Results: Surveys were completed by 399 participants in the dual therapy cohort, and 718 participants in the monotherapy cohort. Following PSM, 379 participants remained in each cohort for analysis (monotherapy: 369 LAMA and 10 LABA). The dual therapy cohort reported fewer COPD-related symptoms (CCQ symptom score 2.75 vs 2.97, respectively, $P=0.023$ ), and, fewer limitations in leisure activities (LCADL leisure score 4.78 vs 5.17, respectively, $P=0.021$ ) versus the monotherapy cohort. No significant differences were found in the WPAI. A greater percentage of participants in the dual therapy cohort stayed on index therapy $(63.1 \%)$ when compared with the monotherapy cohort $(30.3 \%, P<0.0001)$.

Conclusions: Only $30 \%$ of the participants prescribed monotherapy, usually with a LAMA, remained on index therapy alone at the time of survey administration. In the dual therapy cohort, $63 \%$ of the participants remained on the index medication and had fewer COPDrelated symptoms and fewer limitations in leisure activities compared with participants in the monotherapy cohort.

Keywords: muscarinic antagonist, adrenergic beta-agonist, surveys and questionnaires, pulmonary disease, chronic obstructive

\section{Introduction}

Chronic obstructive pulmonary disease (COPD) is characterized by persistent respiratory symptoms and airflow obstruction ${ }^{1}$ and is the fourth leading cause of death in the US after cancer, heart disease, and unintentional injuries. ${ }^{2}$ In 2010 in the US, total medical costs attributable to COPD were estimated at $\$ 32.1$ billion, with an additional $\$ 3.9$ billion in costs due to work absenteeism. ${ }^{3}$ 
The Global Initiatives for Chronic Obstructive Lung Disease $(\mathrm{GOLD})^{1}$ guidelines propose measurement of health status, dyspnea, and number of exacerbations as key outcomes when managing COPD. ${ }^{4}$ Because spirometry is only weakly associated with various health status questionnaires and does not accurately describe the well-being of individuals with $\mathrm{COPD},{ }^{4}$ other outcomes are increasingly important. Patient-reported outcomes (PROs) are recognized as important measurements that reflect the patient's perspective of the impact of the disease on symptom burden, functional capacity, and psychosocial functioning.

The intensity of pharmacological management of COPD can vary depending on a host of factors. The individual's severity of illness as reflected in the degree of symptoms and frequency and severity of exacerbations is of primary importance. GOLD recommends that individuals with more severe COPD involving persistent breathlessness be treated with long-acting muscarinic antagonists (LAMAs) or long-acting beta2-agonists (LABAs), or a combination of the two treatments. ${ }^{1}$ For individuals with two exacerbations in a year or one hospitalization with minimal symptoms, GOLD recommends a LAMA/LABA as a first choice, or an inhaled corticosteroid (ICS) with a LABA (ICS/LABA) for individuals with a history of and/ or findings suggestive of asthma-COPD overlap.

Most clinical evidence shows greater improvements in lung function for individuals on combination bronchodilator therapy compared with the individual drugs alone. A randomized, double-blind, placebo- and active-controlled, 26-week trial ${ }^{5}$ found improved dyspnea and health status with a LAMA/LABA fixed-dose combination (FDC) (QVA149 [glycopyrronium/indacaterol]) compared to LAMA monotherapy (tiotropium). However, real-world data are scarce on the effects of combination therapy in terms of PROs, particularly in comparisons of pharmacological classes.

The primary objective of this study was to compare patient-reported health status (symptoms, functional state, mental state) as measured by the Clinical COPD Questionnaire (CCQ) ${ }^{6}$ in individuals with COPD initiating LAMA/LABA FDC dual therapy versus either LAMA or LABA monotherapy. The secondary objectives were to compare the two cohorts on activities of daily living scores from the London Chest Activities of Daily Living $(\mathrm{LCADL})^{7}$ scale and work productivity and daily activities from the Work Productivity and Activity Impairment $(\mathrm{WPAI})^{8}$ questionnaire.

\section{Materials and methods}

\section{Study design}

This study was a real-world non-interventional study combining a cross-sectional mail-in survey with participants' health care claims data. Adult commercial and Medicare Advantage health plan enrollees were identified using enrollment information (age, gender, plan, dates of eligibility) and medical and pharmacy claims from the Optum Research Database (ORD). The ORD is geographically diverse and nationally representative of the US population and contains data from 1993 to present, covering over 65 million lives. Individuals were invited to participate via a mailed invitation, and a $\$ 25$ gift card was sent to those who returned a survey. The survey was administered once and completed between March 10, 2017 and May 19, 2017. The study protocol received ethics approval and a waiver of authorization from the New England Institutional Review Board (NEIRB). An informed consent statement was provided in the study packet with the survey, and each participant's consent for study participation was implied when the participant completed and returned the survey.

\section{Inclusion criteria}

Individuals were required to be aged $\geq 40$ years as of the year of the index date (ie, first prescription date), and have $\geq 2$ nondiagnostic medical claims $\geq 30$ days apart with an ICD-9-CM or ICD-10-CM diagnosis code for COPD (Table S2) in any position, during the identification period between January 1 , 2016 and December 31, 2016. Individuals were required to have continuous enrollment for 9 months prior to the index date (ie, baseline period), continuous enrollment at the time individuals were being identified for survey invitations, $\geq 1$ pharmacy claim for a LAMA or LABA or LAMA/LABA FDC during the identification period, and any day supply of any of these medications on hand within the month prior to the time individuals were being identified for survey invitation. Finally, individuals had to be eligible to receive a survey invitation, and willing and able to complete surveys in English.

\section{Exclusion criteria}

Individuals were excluded if they had cystic fibrosis, idiopathic pulmonary fibrosis, or asthma during the identification period or 9 months prior to the index date (Tables S3 and $\mathrm{S} 4$ for corresponding codes), $\geq 1$ pharmacy claim for a LAMA, or a LABA, or LAMA/LABA FDC within 3 
months prior to the index date, or $\geq 3$ pharmacy claims for any of these medications within 9 months prior to the index date. These criteria excluded individuals who were adherent to these therapies early in the year but may have stopped in the past 3 months. Also excluded were individuals with $\geq 1$ pharmacy claim for an ICS or ICS/LABA within 2 months prior to the index date.

\section{Index date and cohorts}

The dual therapy cohort included individuals initiating a LAMA/LABA FDC with no prior LAMA, LABA, or LAMA/LABA FDC in the 3 months prior to the index date, and $<3$ fills of any of these medications in the 9 months prior to the index date, and no prior ICS or ICS/ LABA in the 2 months prior to the index date. The index date is the date of the initial pharmacy claim for a LAMA/ LABA FDC during the identification period, with no prior LAMA, LABA, or LAMA/LABA FDC in the 3 months prior to the initial claim and $<3$ fills of LAMA, LABA, or LAMA/LABA FDC in the 9 months prior to the initial claim, and no prior ICS or ICS/LABA in the 2 months prior to the initial claim.

The monotherapy cohort included individuals initiating a LAMA or LABA with no prior LAMA, LABA, or LAMA/ LABA FDC in the 3 months prior to the index date, $<3$ fills of any of these medications in the 9 months prior to the index date, and no prior ICS or ICS/LABA in the 2 months prior to the index date. The index date is the date of the initial pharmacy claim for a LAMA or LABA during the identification period, with no prior LAMA, LABA, or LAMA/LABA FDC in the 3 months prior to the initial claim and $<3$ fills of LAMA, LABA, or LAMA/LABA FDC in the 9 months prior to the initial claim, and no prior ICS or ICS/LABA in the 2 months prior to the initial claim.

\section{Survey contents}

The survey contained questions about demographics, age at COPD diagnosis, access to a health care provider and confirmation by the patient that they were told by a physician or health care professional that they had COPD, emphysema, or chronic bronchitis. Height, weight, smoking status, and COPD therapy utilization were queried. The survey asked which short-acting bronchodilators (rescue medications) were used and the number of days in the last week they were taken, as well as the use of long-acting bronchodilators (index medications) within the last month. The survey included the CCQ, the LCADL, and the WPAI questionnaires.
The CCQ is a 10-item tool that focuses on the clinical status of disease symptoms, functional limitations, and psychosocial dysfunction. ${ }^{6}$ The CCQ provides scores from 0 (very good health status) to 6 (extremely poor health status) for a total score and three domain scores (symptoms, functional state, and mental state). The CCQ was developed to measure clinical control in individuals with COPD, and the total score has been shown to have a correlation of $\mathrm{r}=-0.49(P<0.001)$ with $\mathrm{FEV} 1 \%$ predicted. ${ }^{6}$ The minimal clinically important difference (MCID) for the total CCQ score is $0.4,9,10$ and there are no established MCID values for the domains.

The LCADL scale is a 15 -item tool that measures the effect of dyspnea on routine daily activities. ${ }^{7}$ The LCADL provides a total score from 0 to 75 points with higher scores indicating greater limitations. Domain scores include personal care (0-20), domestic activities (0-30), physical activity (0-10), and leisure (0-15). Good correlations were found with other measures of COPD including the St. George's Respiratory Questionnaire (SGRQ) $(\mathrm{r}=0.70, \quad P<0.0001){ }^{7}$ The minimal detectable change (MDC) for the total score is 3.88 or approximately 4 points, 0.89 for personal care, 2.60 for domestic activities, 0.44 for physical activities, and 0.58 for leisure. ${ }^{11}$

The WPAI is a six-item assessment of the amount of absenteeism, presenteeism, and daily activity impairment attributable to a specific health problem (in this study participants were asked for missed time due to COPD and breathing problems). ${ }^{8}$

\section{Statistical analysis}

The observational study sample was selected from all participants who met inclusion and exclusion criteria. Because study cohorts were not randomized, propensity score matching (PSM) was performed to adjust for confounders between study cohorts. Patients were matched to one another at a 1:1 ratio to create study cohorts with balanced baseline characteristics. ${ }^{12}$ To create the propensity score, a logistic regression model was fitted for participants with monotherapy versus dual therapy as a function of the participants' demographic, clinical characteristics, as well as baseline claims measures. These measures were used as proxies for COPD severity (see Table S5). These model covariates were available up to the index date and thus had the potential to influence assignment of the index drug. Also included in the model as proxies for severity were 10 of the 12 components from Wu's (2006) claimsbased COPD severity score (see Table S5). ${ }^{13}$ An actual 
severity score was not calculated because 12 months of claims were required, and the present study included only 9 months. Anti-cholinergic and long-acting bronchodilators were removed because they were the index medications in this study, and short-acting muscarinic antagonists (SAMAs) were added because baseline counts of SABAs were included as one of Wu's 12 components. After PSM, the difference in baseline variables between cohorts was not significant, supporting that the cohorts were successfully balanced.

Chi-square tests and two-sample $t$-tests were used for comparisons of demographic and outcome measures. Significance tests were two-tailed and carried out at a 0.05 level of significance.

A subgroup analysis was also conducted in which participants were stratified by those who indicated in the survey that they were taking the index medication in the past month and who also had a pharmacy claim for the index medication in the month prior to the survey, versus those who did not have both. All analyses were performed using SAS software version 9.4 (SAS Institute Inc., Cary, NC).

\section{Results}

A total of 887 from the dual therapy cohort and 1,875 participants from the monotherapy cohort were invited to participate, with survey response rates of $46 \%$ and $41 \%$, respectively (Figure 1). Certain surveys had incomplete information (eg, did not have an evaluable CCQ or had not completed at least $80 \%$ of the survey), so the number of participants with surveys eligible for PSM was 388 in the dual therapy cohort and 703 in the monotherapy cohort (682 LAMA and 21 LABA). Following PSM, 379 participants remained in each cohort (Figure 1). The monotherapy cohort consisted of 369 participants receiving a LAMA and 10 participants receiving a LABA. Mean age in the dual therapy cohort was 70.1 years, 53\% were female, $90 \%$ were white, and $14 \%$ were employed. The mean age in the monotherapy cohort was 69.9 years, $50 \%$ were female, $88 \%$ were white, and $9 \%$ were employed.

The dual therapy cohort had a statistically significantly lower mean CCQ symptom domain score compared to the monotherapy cohort $(P=0.023$; Table 1 and Figure 2$)$; however, there are no MCID available for the CCQ domains. No statistically significant difference was found between cohorts in the total CCQ (0.17-point difference was less than the MCID of 0.4), or the functional state or mental state domains. The limitation in leisure activities was found to be less for the dual therapy than monotherapy cohort ( $P=0.021$; Table 1 and Figure 3$)$; however, the 0.39 difference was smaller than the MDC of 0.58 . No statistical or MDC differences were found between cohorts in the other LCADL scores (total, personal care, domestic activities, and physical activities). The dual therapy and monotherapy cohorts had similar work productivity and regular daily activity impairment (WPAI) due to their COPD and breathing problems (Table 1).

\section{Subgroup findings}

Of the 379 participants in the dual therapy cohort, 239 remained on index therapy at the time of the survey (63.1\%) compared to 115 of the 379 participants in the monotherapy cohort $(30.3 \%, P<0.0001)$. The most common switch in the monotherapy cohort was the addition of ICS/LABA to LAMA.

Of the subgroup of participants who remained on index therapy, the CCQ and LCADL mean scores were higher (worse) in the dual therapy compared to the monotherapy cohort (see Table S1); however, there were no statistically significant differences between the two cohorts, or differences that were larger than the MCID for the CCQ or MCD for the LCADL.

There were no statistically significant differences in the WPAI scores, with the exception of more impairment in daily activity in the dual therapy cohort compared to the monotherapy cohort (43.6\% vs $37.1 \%$, respectively, $P=0.048$ ).

Subgroup analyses were also conducted for the CCQ total, LCADL total, and WPAI impairment in daily activities comparing participants who remained on index therapy versus those who did not remain on index therapy, within each cohort. Participants in the monotherapy cohort who did not stay on index therapy had higher (ie, worse) scores compared to those who stayed on index therapy (mean total CCQ 3.01 vs 2.28, difference of $0.73>$ MCID of 0.4 ; mean total LCADL 31.59 vs 25.84 , difference of 5.75> MCD of 3.88; mean WPAI \% impairment $55.0 \%$ vs $37.1 \%$ [no MCID available], respectively; all $P<0.001$ ) (data not shown). Participants who did not stay on index therapy in the dual therapy cohort had higher (ie, worse) mean total CCQ scores compared to those who stayed on index therapy (mean 2.86 vs 2.48 , respectively; $P=0.004$, difference of $0.38<\mathrm{MCID}$ of 0.4 ), and similar trends in the mean total LCADL (30.67 vs 28.06, respectively, $P=0.053$, difference of $2.61<\mathrm{MCD}$ of 3.88 ) and the WPAI impairment in regular daily activity score (49.7\% vs $43.6 \%$, respectively, $P=0.050$ ). 


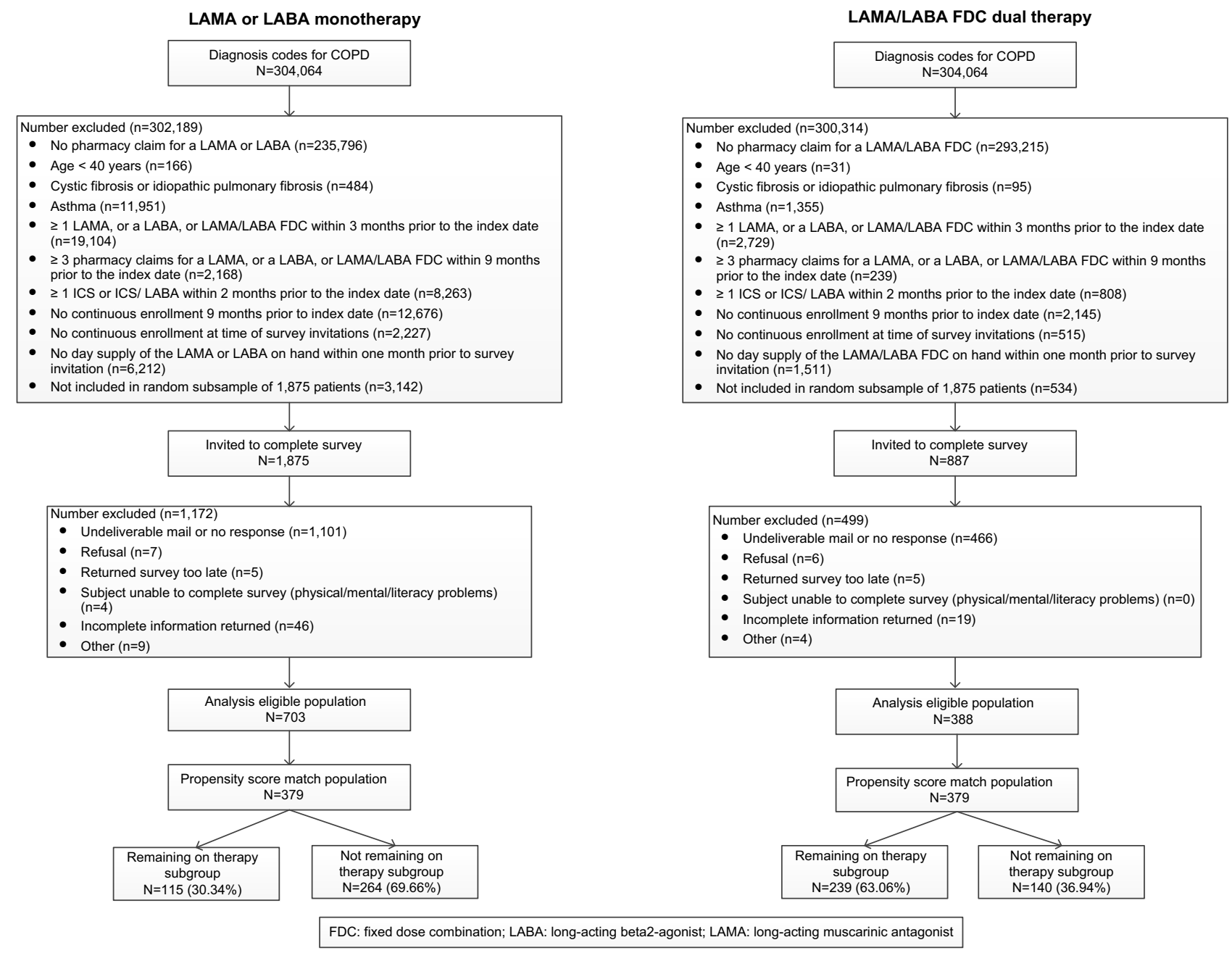

Figure I Flow diagrams for monotherapy and dual therapy cohorts.

Abbreviations: FDC, fixed-dose combination; LABA, long-acting beta2-agonist; LAMA, long-acting muscarinic antagonist.

\section{Discussion}

There are many aspects of real-world observational studies that differ considerably from randomized controlled studies. First, individuals select their treatment regimens with a health care provider in real time. As such, they can transition to alternative regimens quickly. Second, individuals who continue to have activity limitations often add medications. As a result, the timing of PRO surveys can significantly influence study outcomes.

Survey results were strikingly similar between the dual therapy and monotherapy cohorts. Although the dual therapy cohort showed statistically significantly fewer COPD symptoms based on the CCQ symptom score, and statistically significantly fewer limitations in leisure activities based on the LCADL leisure score when compared to the monotherapy cohort, the overall scores of the PRO measures were not different.
It is interesting to note that other studies have found improved COPD symptoms in individuals receiving LAMA/LABA FDC compared to LAMA or LABA monotherapy. A parallel group study (SPARK) conducted by Wedzicha et al (2013) found statistically significantly better health status as measured by a lower total SGRQ score for individuals receiving LAMA/LABA FDC versus LAMA monotherapy, but the difference did not meet the MCID. ${ }^{15}$ However, when Wedzicha compared the percentage of individuals in the FDC versus the monotherapy group achieving an MCID from baseline to target follow-up dates, they found that the FDC group had a significantly greater percentage of individuals meeting the MCID when compared with the monotherapy group. Similarly, a randomized controlled trial conducted by Bateman et al (2013) found significantly better health status as measured by total SGRQ score in individuals receiving LAMA/LABA FDC versus LAMA. ${ }^{5}$ 
Table I Survey questionnaire results for monotherapy and dual therapy cohorts

\begin{tabular}{|c|c|c|c|c|c|}
\hline \multirow[b]{2}{*}{ Primary outcomes } & \multicolumn{2}{|c|}{$\begin{array}{l}\text { LAMA or LABA } \\
\text { monotherapy }\end{array}$} & \multicolumn{2}{|c|}{$\begin{array}{l}\text { LAMA/LABA FDC dual } \\
\text { therapy }\end{array}$} & \multirow[t]{2}{*}{$\begin{array}{l}P \text { - } \\
\text { value }\end{array}$} \\
\hline & $n=379$ & & $n=379$ & & \\
\hline $\mathrm{CCQ}^{\mathrm{a}, \mathrm{b}}$ & Mean (SD) & $95 \% \mathrm{Cl}$ & Mean (SD) & $95 \% \mathrm{Cl}$ & \\
\hline Total $(0-6)$ & $2.79(\mathrm{I} .3 \mathrm{I})$ & $2.66,2.92$ & $2.62(1.26)$ & $2.49,2.75$ & 0.071 \\
\hline Symptoms (0-6) & $2.97(1.36)$ & $2.83,3.10$ & $2.75(1.25)$ & $2.63,2.88$ & 0.023 \\
\hline Functional state $(0-6)$ & $2.60(1.42)$ & $2.45,2.74$ & $2.48(I .4 I)$ & $2.34,2.62$ & 0.253 \\
\hline Mental state $(0-6)$ & $2.82(1.76)$ & $2.64,3.00$ & $2.65(1.77)$ & $2.47,2.82$ & 0.168 \\
\hline \multicolumn{6}{|l|}{ Secondary outcomes } \\
\hline LCADL $^{b}$ & $\mathrm{n}$, Mean (SD) & $95 \% \mathrm{Cl}$ & $\mathrm{n}$, Mean (SD) & $95 \% \mathrm{Cl}$ & \\
\hline Total $(0,75)$ & $354,29.87(|2.8|)$ & $28.53,31.21$ & $363,29.04(12.48)$ & $27.75,30.32$ & 0.376 \\
\hline Leisure activities $(0-15)$ & $373,5.17(2.36)$ & $4.93,5.41$ & $376,4.78(2.32)$ & $4.54,5.01$ & 0.021 \\
\hline Personal care $(0-20)$ & $37 \mathrm{I}, 6.85$ (3.32) & $6.51,7.19$ & $373,6.79(3.23)$ & $6.46,7.12$ & 0.809 \\
\hline Domestic activities (0-30) & $377,12.94(7.52)$ & $12.18,13.70$ & $376,12.86(7.78)$ & $12.07,13.65$ & 0.892 \\
\hline Physical activities $(0-10)$ & $369,4.62(1.86)$ & $4.43,4.8 I$ & $375,4.49(1.62)$ & $4.32,4.65$ & 0.300 \\
\hline WPAI & $\mathrm{n}$, Mean (SD) & $95 \% \mathrm{Cl}$ & $\mathrm{n}$, Mean (SD) & $95 \% \mathrm{Cl}$ & \\
\hline Percent impairment in regular daily activity & $372,49.54(29.42)$ & $46.54,52.54$ & $375,45.84(29.42)$ & $42.85,48.83$ & 0.086 \\
\hline Absenteeism (percent of work time missed) & $33,9.70(25.74)$ & $0.58,18.83$ & $48,5.72(20.82)$ & $-0.32,11.77$ & 0.445 \\
\hline Presenteeism (percent impairment while working) & $35,28.57(28.30)$ & $18.85,38.29$ & $52,18.46(24.12)$ & $11.75,25.18$ & 0.077 \\
\hline Overall work productivity loss (absenteeism + presenteeism) & $33,31.60(31.88)$ & $20.30,42.91$ & $47,22.45(28.27)$ & $14.15,30.75$ & 0.180 \\
\hline
\end{tabular}

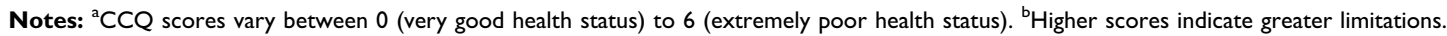

Abbreviations: CCQ, Clinical COPD Questionnaire; Cl, confidence interval; COPD, chronic obstructive pulmonary disease; LABA, long-acting beta2 agonist; LAMA, longacting muscarinic antagonist; LCADL, London Chest Activities of Daily Living; WPAI, Work Productivity and Activity Impairment.

Furthermore, a post-hoc analysis ${ }^{16}$ of subgroups of individuals with COPD in the Bateman study, ${ }^{5}$ based on disease severity, found significantly better SGRQ scores in those receiving LAMA/LABA FDC versus LAMA or LABA monotherapy in the individuals with severe but not moderate COPD.

The most important finding of the current study is that FDC dual therapy initiation leads to a higher persistence of therapy than monotherapy. This finding translates to a higher likelihood of a person being satisfied with the health care encounter if the prescribed therapy meets the person's needs. This finding is supported by lower (ie, better) CCQ, LCADL, and WPAI scores in the participants who stayed on therapy, compared to those who switched (both statistically significantly lower and with an MCID in the monotherapy cohort). The corollary of this finding is that substantial numbers of individuals on monotherapy were actually on triple therapy of ICS/LABA + LAMA at the time of taking the survey, further narrowing the difference in PROs between the two cohorts.

\section{Limitations}

The study design is limited by the lack of a definitive physician diagnosis of COPD. However, during the survey, 93\% of the participants in the dual therapy cohort and $95 \%$ of the participants in the monotherapy cohort confirmed being told by a physician or health care provider that they have COPD, emphysema, or chronic bronchitis. One important limitation of this study was not having spirometry results to include in the PSM that was used for the analysis. However, all available baseline claims covariates were included as proxies for severity, although PSM, like any regression model, does not account for unmeasured confounders. The Quan-Charlson ${ }^{14}$ comorbidity score was included in the PSM, but the analysis did not adjust for individual comorbidities. It is possible that participants in the dual therapy cohort had more severe COPD, thus reducing any differences in participant outcomes between treatment cohorts. It may also be the case that participants included in the study are new to dual therapy or monotherapy. Usually this means that the individuals had moderate COPD, with medications often initiated during or shortly after a COPD exacerbation. Because exacerbations are time-limited events that improve, regression to the mean may have occurred in both cohorts prior to survey completion.

Because LAMA/LABA FDC are recent additions to the market, the administrative claims dataset did not have sufficient individuals on these medications to perform a larger analysis. In the future, similar studies should further limit the time between index medication use and survey completion. Other attempts were made to optimize survey 


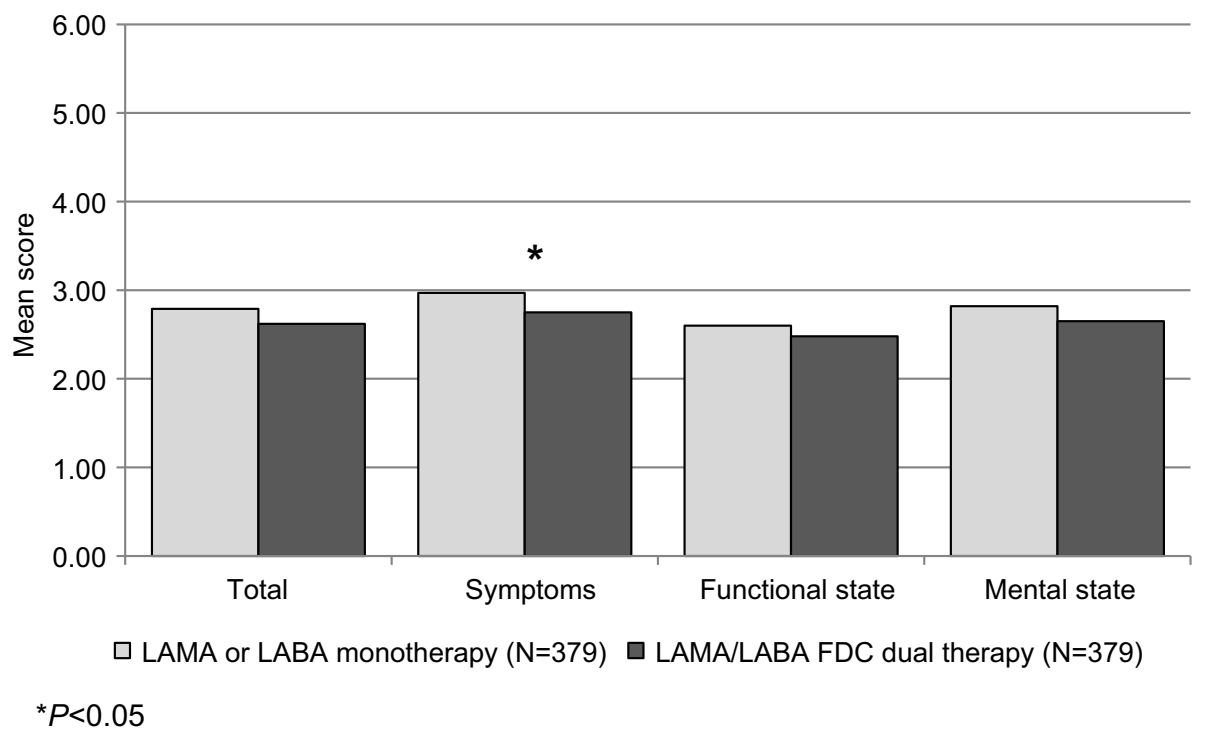

Figure 2 Clinical COPD Questionnaire by LAMA or LABA monotherapy vs LAMA/LABA FDC dual therapy. $* P<0.05$. Clinical COPD Questionnaire scores vary between 0 (very good health status) to 6 (extremely poor health status).

Abbreviations: FDC, fixed-dose combination; LABA, long-acting beta2-agonist; LAMA, long-acting muscarinic antagonist.

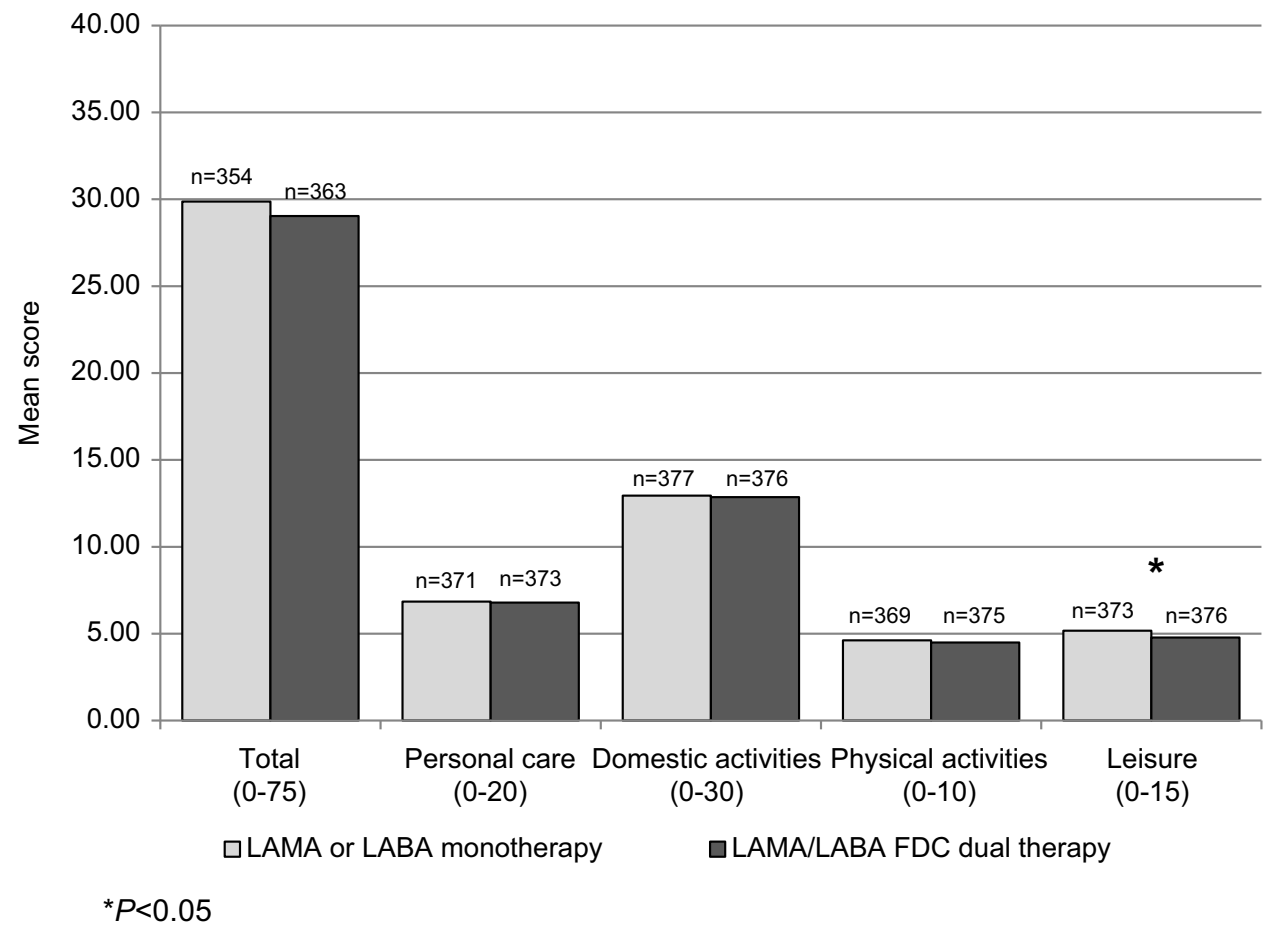

Figure 3 London chest activities of daily living by LAMA or LABA monotherapy vs LAMA/LABA FDC dual therapy. $* P<0.05$. Higher scores indicate greater limitations. Abbreviations: FDC, fixed-dose combination; LABA, long-acting beta2-agonist; LAMA, long-acting muscarinic antagonist.

completion by participants while on the index medication by requiring any days' supply of the index medication on hand within the month prior to study invitation. Unfortunately, this measure did not mitigate this limitation because a large percentage of participants on monotherapy switched therapy prior to survey completion.

\section{Conclusions}

Individuals who initiate on a dual bronchodilator therapy are less likely to switch therapy compared to individuals who initiate on a monotherapy bronchodilator. Participants in the dual therapy cohort reported fewer COPD-related symptoms and fewer limitations in leisure activities 
compared with participants in the monotherapy cohort; however, a causal relationship could not be determined. Future large real-world studies are likely to add value in determining the optimal approach to the treatment of COPD and its impact on patient-reported outcomes.

\section{Data availability}

The data are derived from a database owned by Optum and contains proprietary elements and, therefore, cannot be broadly disclosed or made publicly available at this time. The disclosure of these data to third-party clients assumes certain data security and privacy protocols are in place and that the third-party client has executed Optum's standard license agreement, which includes restrictive covenants governing the use of the data.

\section{Acknowledgments}

We would like to thank Virginia M Rosen, $\mathrm{PhD}$, an employee of Optum Inc, for her assistance in writing this manuscript. This study was funded by AstraZeneca. Optum, Inc. was contracted by AstraZeneca Pharmaceuticals LP to conduct this study and develop the manuscript.

\section{Author contributions}

All authors contributed to data analysis/interpretation, drafting or revising the article, gave final approval of the version to be published, and agree to be accountable for all aspects of the work.

\section{Disclosure}

Dr Charlie Strange reports personal fees and non-financial support from AstraZeneca, CSA Medical, Glaxo Smith Kline, BTG, grants, personal fees, non-financial support from Pulmonx, personal fees from Uptake Medical, and grants from MatRx, all in COPD outside the submitted work. Ms Maureen Carlyle, Mr Jonathan Kurlander, Dr Junliang Tong, and Ms Valery Walker report support from AstraZeneca during the time that this study was conducted. Dr Eric Wittbrodt reports that he is an employee of AstraZeneca. Dr Michael DePietro reports that he was an employee of AstraZeneca during the time that this study was conducted and is currently an employee of Teva Pharmaceuticals. Dr Lauren A Millette reports that she was an employee of AstraZeneca during the time that this study was conducted and is currently an employee of Genentech. The authors report no other conflicts of interest in this work.

\section{References}

1. From the Global Strategy for the Diagnosis, Management and Prevention of COPD, Global Initiative for Chronic Obstructive Lung Disease (GOLD). 2017. Available from: http://goldcopd.org. Accessed November 16, 2017.

2. Kochanek KD, Murphy S, Xu J, Arias E. Mortality in the United States, 2016. NCHS Data Brief. 2017;(293):1-8.

3. Ford ES, Murphy LB, Khavjou O, Giles WH, Holt JB, Croft JB. Total and state-specific medical and absenteeism costs of COPD among adults aged $\geq 18$ years in the United States for 2010 and projections through 2020. Chest. 2015;147(1):31-45. doi:10.1378/ chest.14-0972

4. Tsiligianni I, Kocks J, Tzanakis N, Siafakas N, van der Molen T. Factors that influence disease-specific quality of life or health status in patients with COPD: a review and meta-analysis of Pearson correlations. Prim Care Respir J. 2011;20(3):257-268. doi:10.4104/ pcrj.2011.00029

5. Bateman ED, Ferguson GT, Barnes N, et al. Dual bronchodilation with QVA149 versus single bronchodilator therapy: the SHINE study. Eur Respir J. 2013;42(6):1484-1494. doi:10.1183/09031936.00200212

6. van der Molen T, Willemse BW, Schokker S, ten Hacken NH, Postma DS, Juniper EF. Development, validity and responsiveness of the Clinical COPD Questionnaire. Health Qual Life Out. 2003;1:13. doi:10.1186/1477-7525-1-13

7. Garrod R, Bestall JC, Paul EA, Wedzicha JA, Jones PW. Development and validation of a standardized measure of activity of daily living in patients with severe COPD: the London Chest Activity of Daily Living scale (LCADL). Resp Med. 2000;94:589596. doi:10.1053/rmed.2000.0786

8. Reilly M, Zbrozek A, Dukes E. The validity and reproducibility of a work productivity and activity impairment instrument. PharmacoEconomics. 1993;4:353-365. doi:10.2165/00019053-199304050-00006

9. Smid DE, Franssen FME, Houben-Wilke S, et al. Responsiveness and MCID estimates for CAT, CCQ, and HADS in patients with COPD undergoing pulmonary rehabilitation: a prospective analysis. JAMDA. 2017;18:53-58. doi:10.1016/j.jamda.2016.08.002

10. Kon SS, Dilaver D, Mittal M, et al. The Clinical COPD Questionnaire: response to pulmonary rehabilitation and minimal clinically important difference. Thorax. 2014;69(9):793-798. doi:10.1136/thoraxjnl-2013-204119

11. Bisca GW, Proença M, Salomão A, Hernandes NA, Pitta F. Minimal detectable change of the London chest activity of daily living scale in patients with COPD. J Cardiopulm Rehabil Prev. 2014;34:213-216. doi:10.1097/HCR.0000000000000047

12. Austin PC. Balance diagnostics for comparing the distribution of baseline covariates between treatment groups in propensity-score matched samples. Stat Med. 2009;28(25):3083-3107. doi:10.1002/sim.3697

13. Wu EQ, Birnbaum HG, Cifaldi M, Kang Y, Mallet D, Colice G. Development of a COPD severity score. Curr Med Res Opin. 2006;22(9):1679-1687. doi:10.1185/030079906X115621

14. Quan H, Li B, Couris CM, et al. Updating and validating the Charlson comorbidity index and score for risk adjustment in hospital discharge abstracts using data from 6 countries. Am J Epidemiol. 2011;173(6):676-682. doi:10.1093/aje/kwq433

15. Wedzicha JA, Decramer M, Ficker JH, et al. Analysis of chronic obstructive pulmonary disease exacerbations with the dual bronchodilator QVA149 compared with glycopyrronium and tiotropium (SPARK): a randomised, double-blind, parallel-group study. Lancet Respir Med. 2013;1(3):199-209. doi:10.1016/S2213-2600(13) 70052-3

16. Chapman KR, Bateman ED, Chen H, Hu H, Fogel R, Banerji D. QVA149 improves lung function, dyspnea, and health status independent of previously prescribed medications and COPD severity: a subgroup analysis from the SHINE and ILLUMINATE studies. $J$ Copd F. 2015;2(1):48-60. doi:10.15326/jcopdf.2.1.2014.0140 


\section{Supplementary materials}

Table SI Survey questionnaire results for monotherapy and dual therapy subgroups who remained on therapy

\begin{tabular}{|c|c|c|c|c|c|c|}
\hline & \multicolumn{3}{|c|}{ Participants remaining on index therapy } & \multicolumn{3}{|c|}{$\begin{array}{l}\text { Participants not remaining on index } \\
\text { therapy }\end{array}$} \\
\hline & $\begin{array}{l}\text { LAMA or } \\
\text { LABA mono- } \\
\text { therapy } \\
\text { Mean (SD) }\end{array}$ & $\begin{array}{l}\text { LAMA/LABA } \\
\text { FDC dual ther- } \\
\text { apy } \\
\text { Mean (SD) }\end{array}$ & $\begin{array}{l}P \text { - } \\
\text { value }\end{array}$ & $\begin{array}{l}\text { LAMA or } \\
\text { LABA mono- } \\
\text { therapy } \\
\text { Mean (SD) }\end{array}$ & $\begin{array}{l}\text { LAMA/LABA } \\
\text { FDC dual ther- } \\
\text { apy } \\
\text { Mean (SD) }\end{array}$ & $\begin{array}{l}P \text { - } \\
\text { value }\end{array}$ \\
\hline \multicolumn{7}{|l|}{ Primary outcomes } \\
\hline $\mathrm{CCQ}^{\mathrm{a}, \mathrm{b}}$ & $\mathrm{n}=115$ & $n=239$ & & $n=264$ & $n=140$ & \\
\hline Total $(0-6)$ & $2.28(1.24)$ & $2.48(1.25)$ & 0.155 & $3.01(1.28)$ & $2.86(1.24)$ & 0.256 \\
\hline Symptoms (0-6) & $2.49(1.27)$ & $2.62(1.26)$ & 0.371 & $3.18(1.34)$ & $2.98(1.22)$ & 0.153 \\
\hline Functional State $(0-6)$ & $2.08(1.33)$ & $2.34(1.38)$ & 0.099 & $2.82(1.40)$ & $2.72(1.43)$ & 0.496 \\
\hline Mental State $(0-6)$ & $2.24(1.72)$ & $2.49(1.73)$ & 0.210 & $3.07(1.72)$ & $2.91(1.80)$ & 0.373 \\
\hline \multicolumn{7}{|l|}{ Secondary outcomes } \\
\hline LCADL $^{\mathrm{b}}$ & $\mathrm{n}$, mean $(\mathrm{SD})$ & $\mathrm{n}$, mean (SD) & & $\mathrm{n}$, mean $(\mathrm{SD})$ & $\mathrm{n}$, mean (SD) & \\
\hline Total $(0-75)$ & I06, $25.84(11.44)$ & $227,28.06(12.45)$ & 0.122 & $248,31.59(13.01)$ & $136,30.67(12.40)$ & 0.500 \\
\hline Leisure Activities (0-15) & II $4,4.47(2.20)$ & $236,4.58(2.22)$ & 0.672 & $259,5.48(2.36)$ & $140,5.1 \mid(2.46)$ & 0.140 \\
\hline Personal Care (0-20) & II $3,5.95(2.64)$ & $235,6.57(3.16)$ & 0.055 & $258,7.24(3.5 \mathrm{I})$ & $138,7.16(3.33)$ & 0.826 \\
\hline Domestic Activities (0-30) & II5, II.20 (6.59) & $237,12.48(8.04)$ & 0.114 & $262,13.70(7.78)$ & I39, I3.53 (7.30) & 0.824 \\
\hline Physical Activities (0-10) & $109,4.03(1.7 I)$ & $236,4.39(1.56)$ & 0.053 & $260,4.87(1.87)$ & $139,4.65(1.70)$ & 0.261 \\
\hline WPAI & $\mathrm{n}$, mean $(\mathrm{SD})$ & $\mathrm{n}$, mean $(\mathrm{SD})$ & & $\mathrm{n}$, mean $(\mathrm{SD})$ & $\mathrm{n}$, mean (SD) & \\
\hline $\begin{array}{l}\text { Percent Impairment in Regular } \\
\text { Daily Activity }\end{array}$ & II4, $37.11(28.06)$ & $236,43.56(28.73)$ & 0.048 & $258,55.04(28.36)$ & $139,49.7 \mid(30.26)$ & 0.082 \\
\hline $\begin{array}{l}\text { Absenteeism (percent of work } \\
\text { time missed) }\end{array}$ & $12,8.33(28.87)$ & $30,5.52(19.45)$ & 0.715 & $21,10.48(24.49)$ & $18,6.06(23.50)$ & 0.570 \\
\hline $\begin{array}{l}\text { Presenteeism (percent impair- } \\
\text { ment while working) }\end{array}$ & $12,19.17(25.75)$ & $34,17.35$ (19.90) & 0.803 & $23,33.48(28.86)$ & $18,20.56(31.15)$ & 0.177 \\
\hline $\begin{array}{l}\text { Overall Work Productivity Loss } \\
\text { (absenteeism + presenteeism) }\end{array}$ & 12, $21.67(31.86)$ & $30,23.07(26.31)$ & 0.884 & $2 I, 37.28(3 I .2 I)$ & I7, $21.35(32.26)$ & 0.132 \\
\hline
\end{tabular}

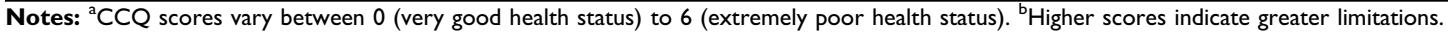

Abbreviations: CCQ: Clinical COPD Questionnaire; COPD, chronic obstructive pulmonary disease; FDC, fixed-dose combination; LABA, long-acting beta2 agonist; LAMA, long-acting muscarinic antagonist; LCADL, London Chest Activities of Daily Living; WPAI, Work Productivity and Activity Impairment. 
Table S2 COPD codes and descriptions

\begin{tabular}{|c|c|c|c|}
\hline ICD-9-CM & Description & $\begin{array}{l}\text { ICD- } \\
\text { I0-CM }\end{array}$ & Description \\
\hline \multicolumn{4}{|c|}{ Codes for COPD } \\
\hline 491.0 & Simple chronic bronchitis & $\mathrm{J} 410$ & Simple chronic bronchitis \\
\hline 491.1 & Mucopurulent chronic bronchitis & J4II & Mucopurulent chronic bronchitis \\
\hline 491.20 & $\begin{array}{l}\text { Obstructive chronic bronchitis, without } \\
\text { exacerbation }\end{array}$ & J449* & Chronic obstructive pulmonary disease, unspecified \\
\hline 491.21 & $\begin{array}{l}\text { Obstructive chronic bronchitis, with } \\
\text { (acute) exacerbation }\end{array}$ & J $44 I^{*}$ & $\begin{array}{l}\text { Chronic obstructive pulmonary disease with (acute) } \\
\text { exacerbation }\end{array}$ \\
\hline 491.22 & $\begin{array}{l}\text { Obstructive chronic bronchitis with } \\
\text { acute bronchitis }\end{array}$ & $\mathrm{J} 440^{*}$ & $\begin{array}{l}\text { Chronic obstructive pulmonary disease with acute } \\
\text { lower respiratory infection }\end{array}$ \\
\hline 491.8 & Other chronic bronchitis & J418 & Mixed simple and mucopurulent chronic bronchitis \\
\hline 491.9 & Unspecified chronic bronchitis & $\mathrm{J} 42$ & Unspecified chronic bronchitis \\
\hline 492.0 & Emphysematous bleb & J439 & Emphysema, unspecified \\
\hline 492.8 & Other emphysema & J438 & Other emphysema \\
\hline 492.8 & Other emphysema & J430 & $\begin{array}{l}\text { Unilateral pulmonary emphysema [MacLeod's } \\
\text { syndrome] }\end{array}$ \\
\hline 492.8 & Other emphysema & J431 & Panlobular emphysema \\
\hline 492.8 & Other emphysema & J432 & Centrilobular emphysema \\
\hline 492.8 & Other emphysema & J439 & Emphysema, unspecified \\
\hline 496 & $\begin{array}{l}\text { Chronic airway obstruction not else- } \\
\text { where classified }\end{array}$ & J449* & Chronic obstructive pulmonary disease, unspecified \\
\hline \multicolumn{4}{|c|}{$\begin{array}{l}\text { Codes for chronic } \\
\text { obstructive asthma }\end{array}$} \\
\hline 493.20 & Chronic obstructive asthma, unspecified & $\mathrm{J} 449 *$ & Chronic obstructive pulmonary disease, unspecified \\
\hline 493.21 & $\begin{array}{l}\text { Chronic obstructive asthma with status } \\
\text { asthmaticus }\end{array}$ & J440* & $\begin{array}{l}\text { Chronic obstructive pulmonary disease with acute } \\
\text { lower respiratory infection }\end{array}$ \\
\hline 493.22 & $\begin{array}{l}\text { Chronic obstructive asthma, with (acute) } \\
\text { exacerbation }\end{array}$ & $J 44 I^{*}$ & $\begin{array}{l}\text { Chronic obstructive pulmonary disease with (acute) } \\
\text { exacerbation }\end{array}$ \\
\hline
\end{tabular}


Table S3 Codes for cystic fibrosis and idiopathic pulmonary fibrosis

\begin{tabular}{|l|l|l|}
\hline Code & Code type & Description \\
\hline 277.00 & ICD-9 Dx & Cystic fibrosis without mention of meconium ileus \\
277.02 & ICD-9 Dx & Cystic fibrosis with pulmonary manifestations \\
277.03 & ICD-9 Dx & Cystic fibrosis with gastrointestinal manifestations \\
277.09 & ICD-9 Dx & Cystic fibrosis with other manifestations \\
E849 & ICD-10 Dx & Cystic fibrosis, unspecified \\
E840 & ICD-10 Dx & Cystic fibrosis with pulmonary manifestations \\
E8419 & ICD-10 Dx & Cystic fibrosis with other intestinal manifestations \\
E848 & ICD-10 Dx & Cystic fibrosis with other manifestations \\
516.31 & ICD-9 Dx & Idiopathic pulmonary fibrosis \\
84III2 & ICD-10 Dx & Idiopathic pulmonary fibrosis \\
\hline
\end{tabular}

Table S4 Codes for asthma

\begin{tabular}{|c|c|c|}
\hline Code & Code type & Description \\
\hline 493.00 & ICD-9 Dx & Extrinsic asthma, unspecified \\
\hline 493.01 & ICD-9 Dx & Extrinsic asthma with status asthmaticus \\
\hline 493.02 & ICD-9 Dx & Extrinsic asthma, with (acute) exacerbation \\
\hline 493.10 & ICD-9 Dx & Intrinsic asthma, unspecified \\
\hline 493.11 & ICD-9 Dx & Intrinsic asthma with status asthmaticus \\
\hline 493.12 & ICD-9 Dx & Intrinsic asthma, with (acute) exacerbation \\
\hline 493.20 & ICD-9 Dx & Chronic obstructive asthma, unspecified \\
\hline 493.21 & ICD-9 Dx & Chronic obstructive asthma with status asthmaticus \\
\hline 493.22 & ICD-9 Dx & Chronic obstructive asthma, with (acute) exacerbation \\
\hline 493.82 & ICD-9 Dx & Cough variant asthma \\
\hline 493.90 & ICD-9 Dx & Asthma, unspecified, unspecified status \\
\hline 493.91 & ICD-9 Dx & Asthma, unspecified with status asthmaticus \\
\hline 493.92 & ICD-9 Dx & Asthma, unspecified, with (acute) exacerbation \\
\hline J4599| & ICD-10 Dx & Cough variant asthma \\
\hline J4550 & ICD-10 Dx & Severe persistent asthma, uncomplicated \\
\hline J455I & ICD-I0 Dx & Severe persistent asthma with (acute) exacerbation \\
\hline J4552 & ICD-10 Dx & Severe persistent asthma with status asthmaticus \\
\hline J4590I & ICD-10 Dx & Unspecified asthma with (acute) exacerbation \\
\hline J45902 & ICD-I0 Dx & Unspecified asthma with status asthmaticus \\
\hline J45909 & ICD-10 Dx & Unspecified asthma, uncomplicated \\
\hline J45998 & ICD-I0 Dx & Other asthma \\
\hline
\end{tabular}


Table S5 Baseline variables used in propensity score matching

\begin{tabular}{|c|c|}
\hline Baseline variables used in propensity score matching & Variable type used in propensity score matching \\
\hline Patient out of pocket health care costs & Categorical -4 categories \\
\hline Patient out of pocket COPD-related health care costs & Categorical - 4 categories \\
\hline Total COPD-related health care costs & Categorical - 4 categories \\
\hline Total all-cause health care costs & Categorical - 4 categories \\
\hline Number of COPD-related ED visits & Dichotomous - Y/N \\
\hline Number of all-cause ED visits & Dichotomous - Y/N \\
\hline Number of COPD-related hospitalizations & Dichotomous - Y/N \\
\hline Number of all-cause hospitalizations & Dichotomous - Y/N \\
\hline Gender & Dichotomous - Y/N \\
\hline Quan-Charlson comorbidity score & Dichotomous - Y/N \\
\hline Baseline use of a nebulizer & Dichotomous - Y/N \\
\hline \multicolumn{2}{|l|}{ Component from the COPD severity score } \\
\hline Hospitalization due to Acute Exacerbation of Chronic Bronchitis (AECB) & Dichotomous - Y/N \\
\hline Oxygen Therapy & Dichotomous - Y/N \\
\hline Emphysema & Dichotomous - Y/N \\
\hline Spirometry Tests & Dichotomous - Y/N \\
\hline Pulmonologist Visits & Dichotomous - Y/N \\
\hline Oral Corticosteroids & Dichotomous - Y/N \\
\hline Inhaled Corticosteroids & Dichotomous - Y/N \\
\hline Short-acting beta2-agonists (SABAs) & Dichotomous - Y/N \\
\hline Short-acting muscarinic antagonists (SAMAs) & Dichotomous - Y/N \\
\hline Age & Continuous \\
\hline
\end{tabular}

\section{Publish your work in this journal}

The International Journal of COPD is an international, peer-reviewed journal of therapeutics and pharmacology focusing on concise rapid reporting of clinical studies and reviews in COPD. Special focus is given to the pathophysiological processes underlying the disease, intervention programs, patient focused education, and self management protocols. This journal is indexed on PubMed Central, MedLine and CAS. The manuscript management system is completely online and includes a very quick and fair peer-review system, which is all easy to use. Visit http://www.dovepress.com/testimonials.php to read real quotes from published authors. 